\title{
Measurement and analysis of certain flight parameters based on MEMS sensors
}

\author{
Jerzy Bakunowicz ${ }^{1}$ and Paweł Rzucidło ${ }^{2}$ \\ ${ }^{1}$ Department of Aircraft and Aircraft Engines, Faculty of Mechanical Engineering and Aeronautics, Rzeszow \\ University of Technology, \\ al. Powstancow Warszawy 12, 35-959 Rzeszow, Poland \\ ${ }^{2}$ Department of Avionics and Control, Faculty of Mechanical Engineering and Aeronautics, \\ Rzeszow University of Technology, al. Powstancow Warszawy 12, 35-959 Rzeszow, Poland
}

Correspondence to: Paweł Rzucidło (pawelrz@prz.edu.pl)

Received: 4 November 2016 - Revised: 4 February 2017 - Accepted: 5 April 2017 - Published: 12 May 2017

\begin{abstract}
Gyroscopes established one of the fundamental references for attitude and heading in aerospace applications. The information about angular velocities gives input not only for autopilot, but also damping devices, such as yaw or pitch dampers for example. The MEMS (micro-electro-mechanical system) gyroscopes are much less reliable than their laser or fibre-optic cousins. Nevertheless, the availability and low price of MEMS components make this a growing area of application in avionics for general aviation aeroplanes. This paper presents certain results of flight data analysis registered during the flight testing campaign of the new experimental lowpower single-engine turbo-propeller utility aeroplane I-31T. The research was focused on identification of oscillation modes, distinctive for the new aeroplane, such as engine precession or shimmy. The data came from a three-axis MEMS gyroscope and accelerometer recorder, placed near to the centre of gravity. Wavelet transform, which was used for analysis, gave better precision in time domain than Fourier transform, especially for signals of low frequency.
\end{abstract}

\section{Introduction}

Development in the field of aeronautical engineering is always connected with research activities of high risk. The incessant rush to improve introduced solutions entails desire for their immediate implementation from one side. On the other, however, we are dealing with the quite natural conservatism of putting the protection of human life first. The awareness of this great responsibility accompanied designers from the very beginning - the Wright brothers, while manufacturing their aeroplane, known later as No. 1, considered the strength of each element to cope with weight 5 times greater than the mass of the pilot (McFarland, 1953). The methodology of research has been established and proven, starting from ground static and stiffness tests to testing in flight (Doolittle, 1923). Within decades, they were supplemented by many other tests that are seen as necessary today, such as flutter, vibration, and fatigue, to mention but a few of the most important factors. The whole array of tests and trials before putting a new aeroplane to the market has only one goal - to eliminate all unwelcome features which may negatively affect its future career. In the course of technological progress, the metrologies advance, giving wider cognitive abilities through more accurate and more extensive registration abilities, as well as practically any form of processing and presenting results. However, the benefit of progress is giving rise to negative side effects in the form of extending the time of research works, and hence their cost, the number of different systems and the need for their mutual harmonizing. As a result, the number of new aerospace vehicles is decreasing constantly, compared to the rising costs of development. The so-called 14th Augustine's law gives an excellent illustration (Augustine, 1987), showing in a subversive manner how the cost escalation of US Air Force airborne research programs functions: in the year 2054, the entire defence budget will purchase just one aircraft. The aircraft will have to be shared by the Air Force and Navy, 3.5 days each per week, 
except for leap year when it will be made available to the Marines for the extra day. The simplification of metrologies, measurement software and hardware and the tests at large would seem reasonable in the light of budget optimizing. Test planning should follow the search for new applications of advanced but generally simple metrologies in unexplored areas. A significant indicator for the new application would be the number of parameters and number of samples measured during the test. The methods utilizing a reduced number of entry parameters become crucial for total time of the test program, especially in-flight. As an example one may recall a group of "bootstrap" methods (Lowry, 1999).

One of the most important pieces information recorded during the flight, furthermore not only in the development phase, but also during the entire life of the structure, is the flight load spectrum of the whole airframe as well as its individual parts (Norton, 1990). Early attempts to record flight loads in an organized manner coincide with the dawn of aviation (Doolitle, 1923). Familiarity with aeroplane accelerations not only gives information about the load factor that the structure is exposed to during sustained or instantaneous manoeuvres, but the coupling of the load magnitude and exact aeroplane attitude in the time history also enables the location of a load spectrum, inevitable for preparation of longterm ground fatigue tests. The essence of such data might be underlined by the fact that their importance does not terminate when the fatigue durability tests of the new structures were successfully completed. There may come time for revisiting the data when the aeroplane has served for many years and problems of ageing appear (Guillaume et al., 2014).

Increasing the sampling frequency of the measurement device gives the ability to register not only low-cycle flight loads, but also faster spectra such as vibrations originated by propulsion or turbulence, as well as aero-elastic response of the structure (Wright and Cooper, 2015). Proper comparison of this data with the results of ground vibration tests (GVTs) provides a basis for identification of resonance.

The gyroscopes belong to the group of sensors widely utilized for low and high cycle load recording. MEMS accelerometers in the 1990s found their application to airbag-activation systems in automotives. But they become widespread in household and hobby-craft electronics due to their small size and relatively low price. The aerospace industry absorbed them as well, especially in avionics for general aviation light aeroplanes (Liu et al., 2012; Kopecki and Rogalski, 2013; Rydlo et al., 2013) or on-board RPASs (please refer to Appendix A for abbreviation definitions; Naruoka et al., 2009; Kopecki et al., 2013).

The paper presents an example of MEMS sensor application in light aeroplane flight testing. The research program included measurement system selection, installation and calibration as well as analysis of flight data. Based on experience gained in previous projects, authors concentrated on application of the modified system on board of the aeroplane and identification of characteristic phenomena during differ-

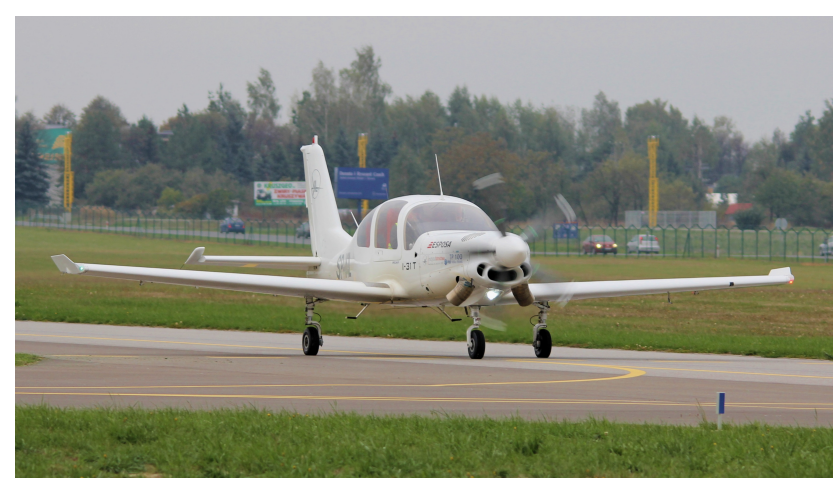

Figure 1. The I-31T aeroplane after one of the test flights.

ent phases of flight. The paper is divided into five sections. Section 2 includes a short description of the new aeroplane and the flight test preparation and methodology. Section 3 presents the airborne measurement system as well as concerns about problems of sensor selection and calibration. In Sect. 4, there is a discussion of the results of several flight examples with unique frequency representations of different flight phases. The conclusions in the final section (Sect. 5) summarise the paper. The main goal of this contribution is to present issues concerning acceleration spectrum flight analysis with continuous wavelet transform using data obtained from devices based on MEMS gyroscopes.

\section{The aeroplane and flight testing campaign}

The measurements took place on the I-31T aeroplane (Fig. 1), the advanced modification of the I-23 Manager aeroplane (Baron, 2012). Both crafts were designed in the Institute of Aviation, Warsaw, Poland. The origins of the aeroplane reach back to the early 1990s. This light, pistonengine-powered, high-performance aeroplane, equipped with advanced avionics, belonged to the chain of the Small Air Transport System project (Piwek and Wiśniowski, 2016). Following worldwide crisis in the general aviation sector, only one sole prototype of I-23 has been built. But the idea to build a transportation system in Europe with doorto-door operation time of less than $4 \mathrm{~h}$ lingered in people's minds (Majka, 2014). The introduction of low-power (below $200 \mathrm{~kW}$ ) turbine engines for propeller propulsion provided the opportunity to create a prototype of a new aeroplane class, reconciling the handling and performance of a light general aviation aeroplane with the economy and simplicity of a turbo-propeller engine.

The I-31T aeroplane has been designed and manufactured as one of several technology demonstrators in the large, international, collaborative European project ESPOSA (Efficient Systems and Propulsion for Small Aircraft) co-funded by European Commission with the 7th Framework Program (ESPOSA, 2016). The concept of a new aeroplane class has 
been proven during the flight test campaign led by Institute of Aviation, Warsaw, together with Rzeszow University of Technology. But the fundamental remark for similar future initiatives says that this class of aeroplanes must not be developed by ordinary conversion of previously piston-driven aeroplanes into turbine-driven aeroplanes. The design should be dedicated for the propulsion exclusively to share all benefits of the new propulsion (Bakunowicz, 2017).

The flight test campaign of the new I-31T aeroplane covered all items described in CS-23 requirements, necessary to prove conformity (EASA, 2009). However, the I-31T aeroplane does not have a type certificate according to EASA CS-23. It is a purely experimental aeroplane, tested under Polish national regulations. The flight test program included tests compliant with CS-23 requirements, but there were several features of the aeroplane revealed which did not fit into EASA margins.

The flight test campaign was organized in a rather classic, conservative manner, bearing in mind the simplicity of the aeroplane. The main recording of the flight parameters has been left for the "eye and hand" of the flight test engineer (FTE), who was accompanying the test pilot during the flight. Independent recording devices were used as supplements for certain measurements of a rather scientific nature, e.g. temperature distribution or engine vibrations. The system used for data analysis in this paper is described in the following section.

\section{Flight data measuring system}

\subsection{General description}

The flight data recorder (FDR) was installed on-board the aeroplane, inside the cabin and close to the centre of gravity, using special attachments to the airframe structure (Fig. 2). It recorded the following parameters with a sampling frequency of $50 \mathrm{~Hz}$ each (Kopecki and Rzucidło, 2014):

- accelerations $a_{x}\left(n_{x}=a_{x} / g\right), a_{y}\left(n_{y}=a_{y} / g\right)$, $a_{z}\left(n_{z}=a_{z} / g\right)$;

- angular velocities $p, q, r$;

- orientation angles $\Phi, \Theta, \Psi$;

- static pressure $P_{\mathrm{s}}$;

- GPS navigation data (positioning at $10 \mathrm{~Hz}$ update rate).

The recorder is a highly modified version of the device designed and manufactured in Rzeszow University of Technology for a PW-6U glider flying laboratory (Bakunowicz et al., 2016; Rzucidło et al., 2016) used in the second edition of the Advanced In-Flight Measurement Techniques (AIM2) project. The system is based on the CAN bus network and CAN bus aerospace protocol. This guarantees the open structure and offers the possibility of further modular development.
The FDR consists of three main hardware modules: power supply and wiring, a central computer with external interfaces, and a measurement module, as seen in Fig. 3. The measurement module has a dedicated processor for data acquisition from the sensors, as well as initial data processing and communication with CAN buses. The sensors and algorithms allow the system to be an integrated AHRS, ADC and GNSS package.

\subsection{Sensors}

FDRs record data from four groups of sensors: accelerometers, gyroscopes, pressure sensors and satellite navigation modules. Below, the details concerning accelerometers and gyroscopes are presented.

The MEMS motion sensor is an ultra-stable three-axis digital output gyroscope. The measurement range of this sensor was selected as \pm 500 degree $^{-1}$. For this range and at stable voltage of $3.0 \mathrm{~V}$, the manufacturer declares performance to be as follows:

- sensitivity 0.017 degree $^{-1}$,

- sensitivity change vs. temperature $\pm 2 \%$ (from -40 to $\left.+85^{\circ} \mathrm{C}\right)$,

- non-linearity $0.2 \%$,

- rate noise density $0.03 \frac{\text { degree }}{\mathrm{s}} \frac{1}{\sqrt{\mathrm{Hz}}}$.

RMS of angular rate noise can be calculated from Eq. (1) and it was estimated as 0.33 degree $^{-1}$ at $50 \mathrm{~Hz}$ sampling frequency.

$\mathrm{RMS}=1.57 \cdot \mathrm{SD} \cdot \sqrt{f}$

The MEMS acceleration sensor is an ultra-compact, highperformance 3-D accelerometer integrated with 3-D magnetometer. The measurement range of this sensor was selected as $\pm 2 \mathrm{~g}$. For this range and at stable voltage of $2.5 \mathrm{~V}$, one may expect (according to the manufacturer's data sheet) acceleration noise density $0.000220 \mathrm{~g} \sqrt{\mathrm{Hz}}^{-1}$. Calculated RMS of acceleration noise at $50 \mathrm{~Hz}$ is equal to $0.0024 \mathrm{~g}$. Linear acceleration sensitivity change vs. temperature is $\pm 0.01 \%{ }^{\circ} \mathrm{C}^{-1}$.

The calibration of MEMS sensors encompassed calculation of the scale and offset coefficients which were recorded into sensor's settings. For the calculation of the calibration coefficients, the least-square method was applied. The rotational table (Fig. 3) was used for the experiment (Kopecki and Rzucidło, 2014). The calibration procedure was realized with the use of algorithms presented in Sipos (2012). This method relies on the suggestion of optimal positions, in which the calibration procedure takes place.

The gyroscopes were calibrated for values of angular velocity in the range from 0 to 300 degree $^{-1}$ as follows: $\pm 15, \pm 30, \pm 50, \pm 100, \pm 150$ and \pm 300 degree $^{-1}$. The accelerometers were calibrated in range of $\pm 1 \mathrm{~g}$ for values of 

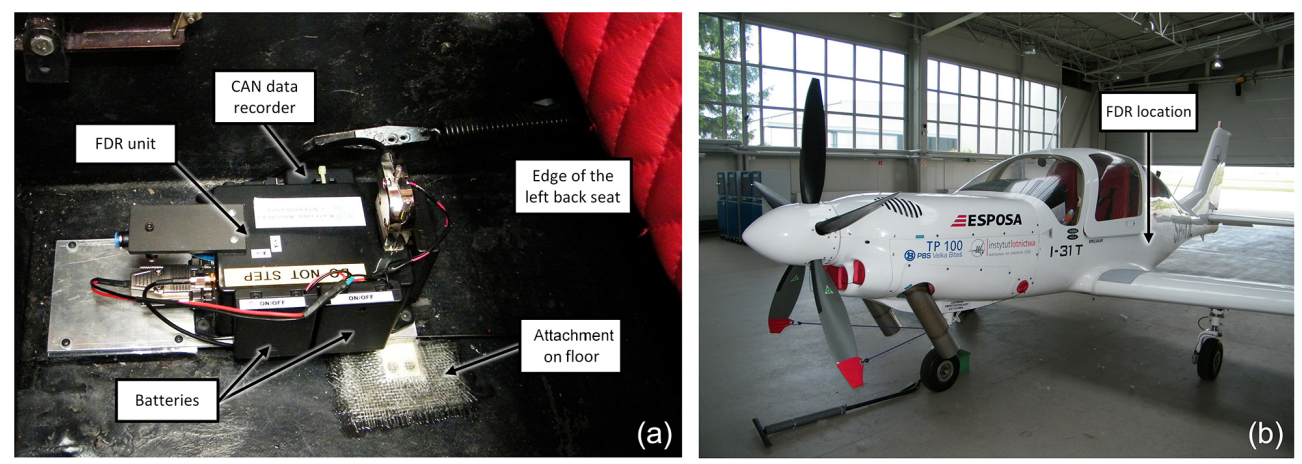

Figure 2. FDR installed on the board of I-31T (a); general view of I-31T and indication of FDR location (b).
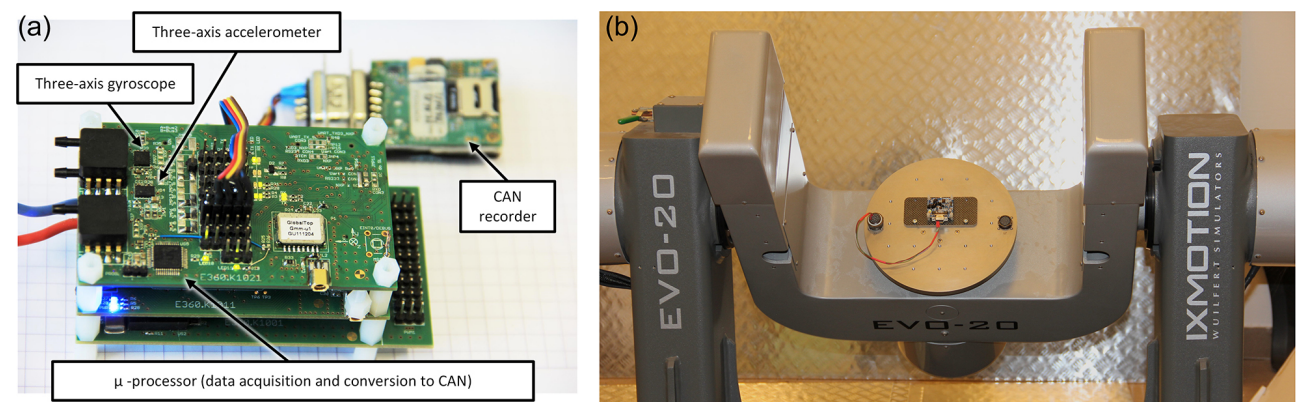

Figure 3. Hardware modules of FDR (a); rotational table used for calibration and testing of MEMS gyroscopes and accelerometers (b).

$-1,0,+1 \mathrm{~g}$. The sensors were examined in three perpendicular axes in the same manner. The results showed that the gyroscopes have linear characteristics within a range of $\pm 300^{\circ}$ and accelerometers have linear characteristics within a range of $\pm 1 \mathrm{~g}$.

In order to check the measurement uncertainty of the sensors, RMS values were calculated for recordings of $10^{6}$ samples of every parameter with a frequency of $50 \mathrm{~Hz}$ in static state. RMS obtained for accelerometers $n_{x}, n_{y}$ and $n_{z}$ was $0.0019,0.0021$ and $0.0052 \mathrm{~g}$, respectively, and for gyro-

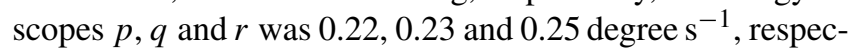
tively.

Stochastic characteristics of sensors were also investigated using GMWM method (Guerrier et al., 2013). Figure 4 presents empirical wavelet variance of measured data ( $10^{6}$ observations per parameter). The GMWM results allowed the estimation of parameters of process noise which were compared with WV values for optimised sensor models and real sensors (Fig. 4). Plots presented in Fig. 4 allow us to understand what kind of processes are contributing to the overall error model. For example, error models of accelerometer $X$ and gyroscopes $X$ and $Z$ can be specified using a combination of a first-order autoregressive process (AR1) and random walk (RW) process. Additionally, a white noise (WN) process is contributing error models of other sensors.

\subsection{Installation and operation on board}

The measurement device was installed on-board the aircraft as an independent item, separate from the systems and installations of the aircraft. The electronics were placed inside the plastic box and stiffly rigged via assembly plate to the airframe structure in order to record accelerations without damping. The FDR had its own power source which enabled continuous work over a $6 \mathrm{~h}$ duration. The FDR was put into operation before the flight by FTE and switched off after landing. The data set, recorded on an SD memory card, was transferred onto a PC hard disk and processed in dedicated commercial software as well as software created in-house. Besides the independent, impartial data recording by the FTE and FDR, the opinions of the test pilots about the handling as well as other feelings were collected in a disciplined manner (Harper and Cooper, 1986).

\section{Measurements results and discussion}

This section deals with examples of cycle load spectrum analysis recorded during test flights. The emphasis has been laid on the landing phase and movement of the aeroplane on the ground, due to the fact that these recordings initiated presented research. 


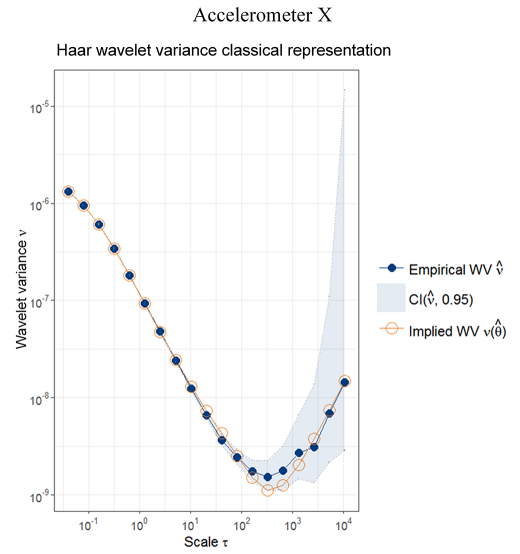

Estimated model: $2 *$ AR1()+RW()

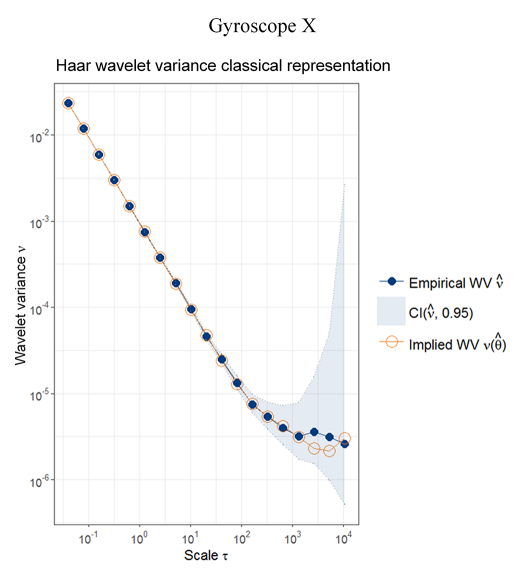

Estimated model: $3 *$ AR 1()$+$ RW()

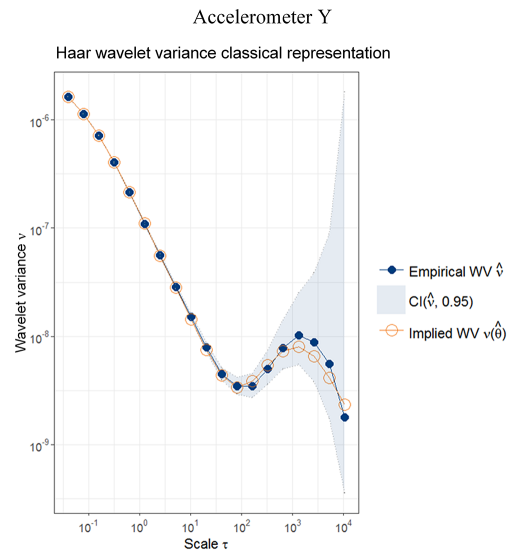

Estimated model: 2*AR1()+WN()+RW()

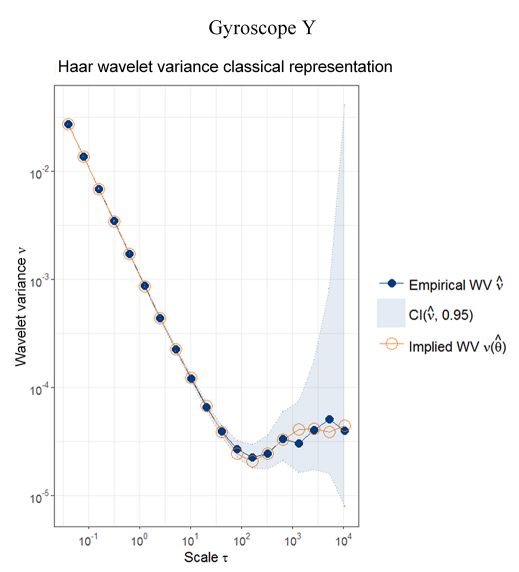

Estimated model: $3 *$ AR1()+WN()+RW()

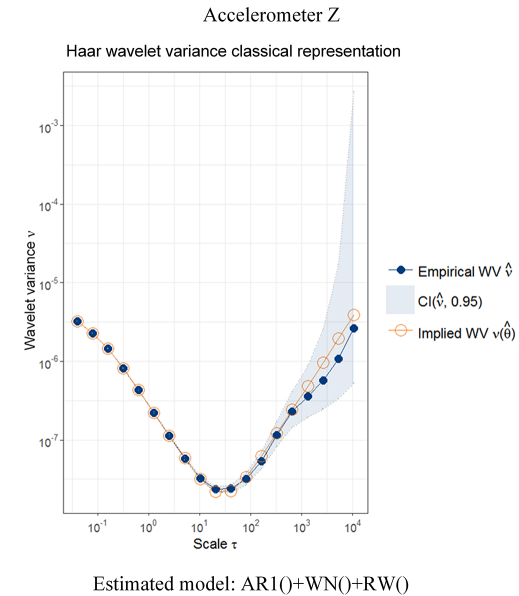

Gyroscope Z

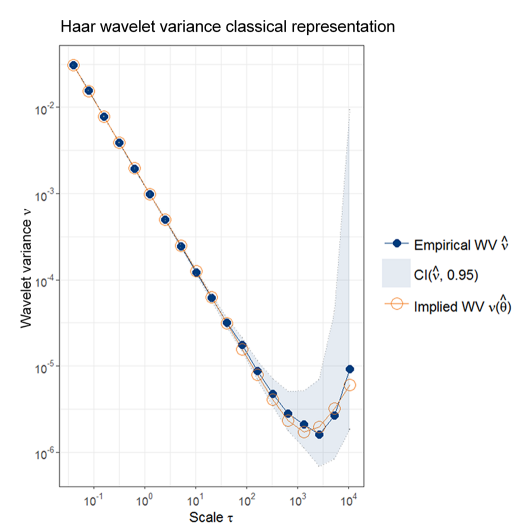

Estimated model: 4*AR1()+RW()

Figure 4. Wavelet variance calculated for $10^{6}$ observations, sensor WV and models identified with the use of the GMWM method (Balamuta et al., 2016).

\subsection{Landing and ground manoeuvres}

The I-31T aeroplane operated from concrete runway surfaces. Its approach and landing qualities were assessed between 4 and 5 grade in the Cooper-Harper scale (Harper and Cooper, 1986). The aeroplane has a wing loading of $115 \mathrm{~kg} \mathrm{~m}^{-2}$, which places it in the upper range among similar aeroplanes. This implies a high approach and high landing speeds. Additionally, high effectiveness of elevator and marginal longitudinal stability, decreased by a long nose of the new propulsion, require higher pilot concentration. The flare phase is rather figurative. To summarize, the aeroplane is characterized by short landings in a "carrier-like" style.

One of many landings, at three wheels and quite "hard", on wet runway with centreline lamps touched by the front wheel during roll-off, finished with shimmy vibrations of the front undercarriage, which ceased when the aeroplane came to a halt completely.

Shimmy occurs when a wheel oscillates at often large amplitudes about its vertical axis, around which the wheel rotates. For light aeroplanes it is common for front gears with one wheel and manifests itself as a limit cycle oscillation with a frequency range typically $10-30 \mathrm{~Hz}$. The most common reasons are inadequate torsional stiffness, torsional freeplay, wheel imbalance, etc. It is normally countered by careful design or use of dampers. The I-23 aeroplane, progenitor of the I-31T, has been equipped with shimmy damper during her flight test campaign, but it was removed and no complaints have been recorded so far. Indeed, a quick maintenance check after this particular shimmy incident revealed an excessive freeplay in the front steering mechanism.

The vibrations of the aeroplane during roll-off, caused by shimmy of the front gear, were clearly recognizable by the crew and felt on the background of other motions of the aeroplane. Therefore, it might be assumed, the FDR should also register them in a certain manner, e.g. oscillations of angular velocities or linear accelerations.

In the first step, several recordings of different landings, including final approach, flare, touchdown and roll-off, were investigated. The key to distinguishing the moment that the 

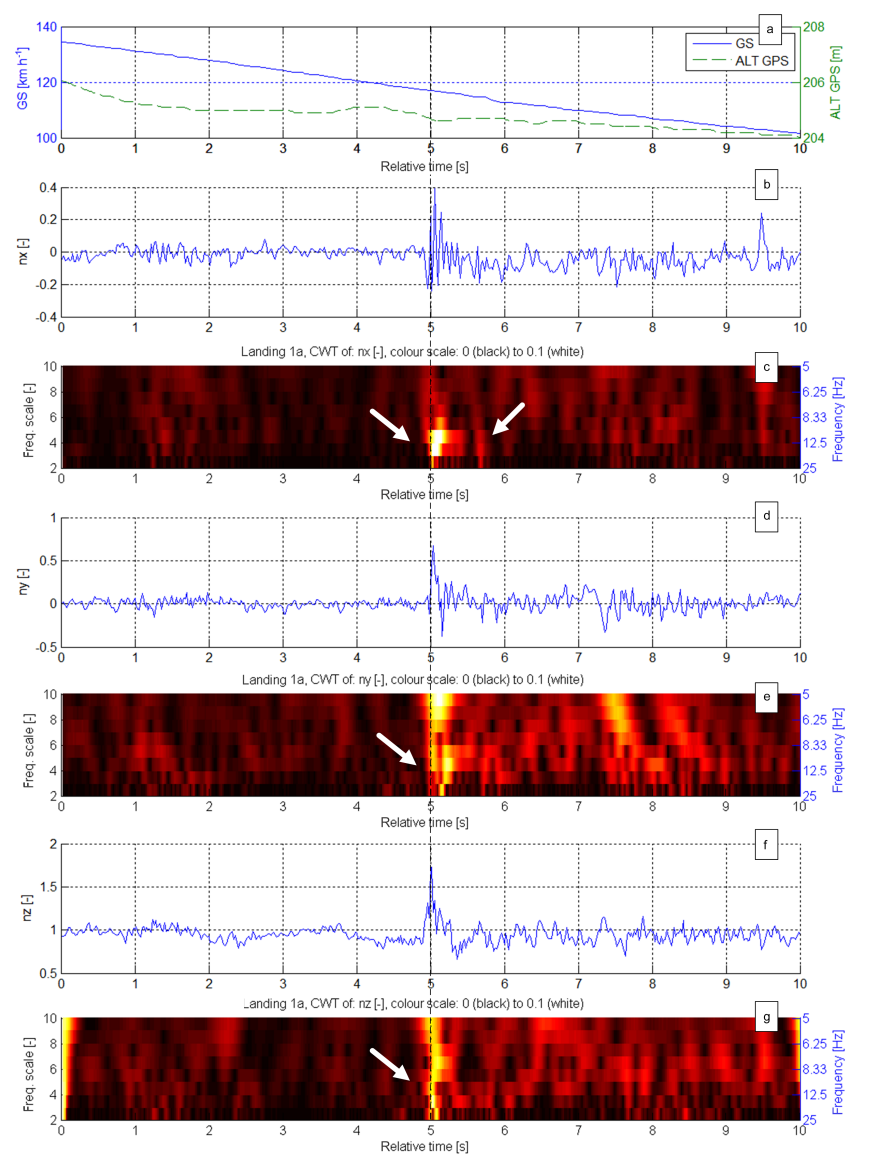

Figure 5. CWT analysis graphs for main and front-gear touchdown moment detection (landing No. 1a). Charts present (a) altitude (m), ground speed $\left(\mathrm{km} \mathrm{h}^{-1}\right),(\mathbf{b}) n_{x}(-),(\mathbf{c})$ CWT analysis of (b), (d) $n_{y}$ (-), (e) CWT analysis of (d), (f) $n_{z}(-),(\mathbf{g})$ CWT analysis of (f), in time domain span 10 (s), respectively.

aeroplane leaves the air and starts to ride on the ground is the identification of wheel contact with the pavement. The main gear contact was identified by analysis of $n_{z}$ change vs. change of altitude and ground speed (Fig. 5a, f-g). The touch of the front gear is more visible after continuous wavelet transform (CWT) of all three components of acceleration $n_{x}$, $n_{y}$ and $n_{z}$ (Fig. 5c, e, g). But the most repeatable results, regardless of the landing quality, were obtained for the $n_{x}$ component. There is always short-term vibration along the longitudinal axis (Fig. 5c), which concentrates close to the value of 5 on frequency scale (that means $10 \mathrm{~Hz}$, according to pseudo-frequencies).

The frequency as well as amplitude of $n_{x}$ oscillations is not correlated with $n_{z}$ component, which denotes the "hardness" of the landing. Therefore CWT analysis of $n_{x}$ may be sufficient for effective touch-down identification with an accuracy of $50 \mathrm{~ms}$. The colour shade in Fig. 5c, e and g denotes vibration amplitude. Black is equal to "zero" and white denotes limit amplitude, defined as a colour scale in CWT charts. A complex Morlet wavelet was used as analysis function (Abbate et al., 2002).

The landing analysed in Fig. 5 (landing no. 1a) may be assumed to be a regular one with smooth touch-down. During roll-off there were no disturbing phenomena. Shimmy vibrations appeared during the roll-off recorded in landing no. 2a (Fig. 6). This kind of oscillatory movement is hard to identify in acceleration and angular velocity time plots; however, they manifest as high-frequency occurrence (frequency scale 2 to 10) from the 2nd to 7th second in CWT chart of $n_{y}$. In the 4th second there is short-pulse braking action of the pilot (Figs. 6b-c, 7c-d) that caused an unexpected increase in amplitude. When the aeroplane groundspeed was below $75 \mathrm{kph}$ (Fig. 6a), the vibrations of high amplitude occurred, clearly visible as a change in acceleration along the $y$ axis (Fig. 6de). Similar characteristics may be found on time plots as well as on CWT charts of $n_{z}$ (Fig. 3f-g) and velocities $p$ and $r$ (Fig. 7a-b and e-f). The analysis of $n_{x}$ load and angular velocity $q$ reveals two attempts at braking action initiated by the pilot between 11.5 and $13 \mathrm{~s}$, and afterwards from 18.5 to $24 \mathrm{~s}$. Each breaking increased the amplitude with maximums recorded in 12.5, 19 and $23 \mathrm{~s}$ respectively. In the $23 \mathrm{rd}$ second, vibrations of $n_{y}$ reached 1 , and remaining $n_{x}$ and $n_{z}$ had amplitudes lower by half.

One may notice, analysing CWT charts of $n_{y}$ and $p$ in Figs. $6 \mathrm{e}, 7 \mathrm{~b}$, that between seconds 2 and 14 the spectrum is dominated by vibrations with frequencies of $5-25 \mathrm{~Hz}$. In second 17 and further, when the aeroplane groundspeed decreased below $60 \mathrm{kph}$, high-amplitude vibrations of $n_{y}$ and $p$ rose gradually, having frequencies in the middle of the scale, between 2.5 and $5 \mathrm{~Hz}$ (Figs. 6e, 7b). The other accelerations and angular velocities were affected similarly, but with much less effect (Figs. 6-7). After second 24, when the aeroplane groundspeed decreased below $40 \mathrm{kph}$, the vibrations ceased. The pilot claimed that the only possible solution to damp the vibration was to halt the aeroplane. Rolling with the groundspeed higher than $40 \mathrm{kph}$ caused an increase in the amplitude. It should be highlighted that no other landing, in the set of 20 recorded, contained similar characteristics during roll-off.

The vibrations described above and recorded by FDR represent the effect of interaction between shimmy oscillatory movement of the front gear and the rest of the airframe, and finally the FDR itself. Therefore this spectrum (frequencies and amplitudes) does not represent the behaviour of the undercarriage, and cannot be applied directly. Moreover, the shimmy vibrations belong to the oscillatory movements with more than 1 degree of freedom. But concerning the effects of shimmy vibrations on the rest of the airframe, the spectrum in this form would give useful information about frequencies and "severity" of the vibrations.

Figures 8 and 9 present aeroplane roll-off after flight no. 3 . For the best comparison of two roll-offs CWT results (with and without shimmy), the contour plot spectrum scale remained the same $\left(0.05\right.$ for accelerations and 0.75 degree $\mathrm{s}^{-1}$ for angular velocities). Oscillations characterised by large 

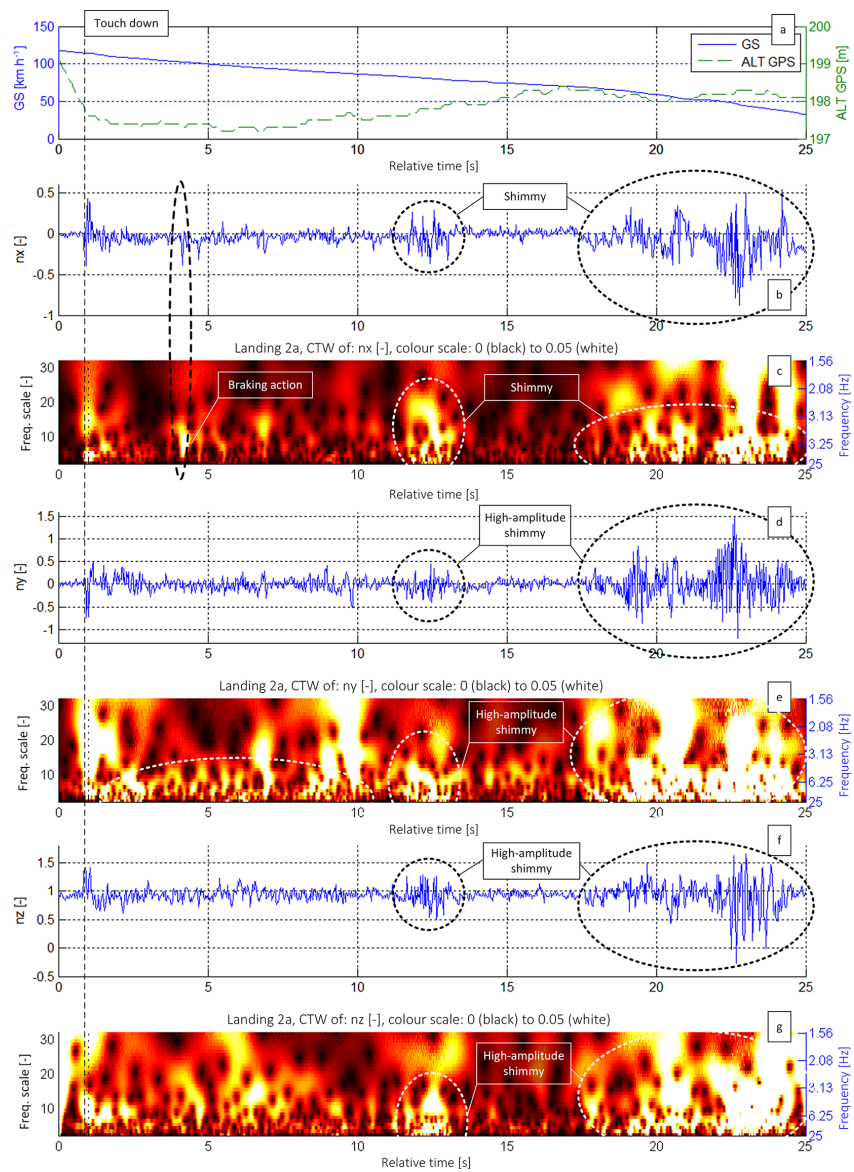

Figure 6. Load-factor analysis, recorded during the roll-off with shimmy vibrations of the front gear (CWT analysis); landing no. $2 \mathrm{a}$.

amplitudes (similar to the landing no. 2a) occur only within first $10 \mathrm{~s}$ after touchdown for $n_{y}$ and $p$. This is the result of pulse-braking initiated in 8th second. The first attempt was asymmetric, resulting in oscillations in the roll. After $13 \mathrm{~s}$, the speed decreased below $70 \mathrm{kph}$, and oscillations ceased or were damped by the pilot's action. Pulse-braking lasted between the 10th and 20th second.

\subsection{Short flight general analysis}

Figure 10 presents the whole recording from the short "hoop" flight between two parallel runways. There are angular velocities $p, q, r$ in the time domain (Fig. 10b, e and h) starting from the short holding time before take-off and terminating when the aeroplane is taxiing to the apron (Fig. 10a). This analysis does not present accelerations, due to troublesome interpretation of a vast number of oscillations.

In Fig. 10 take-off and touch-down were identified. Note that in the CWT chart of $p$ angular velocity (Fig. 10c-d), when the aeroplane is on the ground the spectrum is dominated by high frequencies from the engine. During roll-on and roll-off, they are close to $3 \mathrm{~Hz}$, but there is no distinction
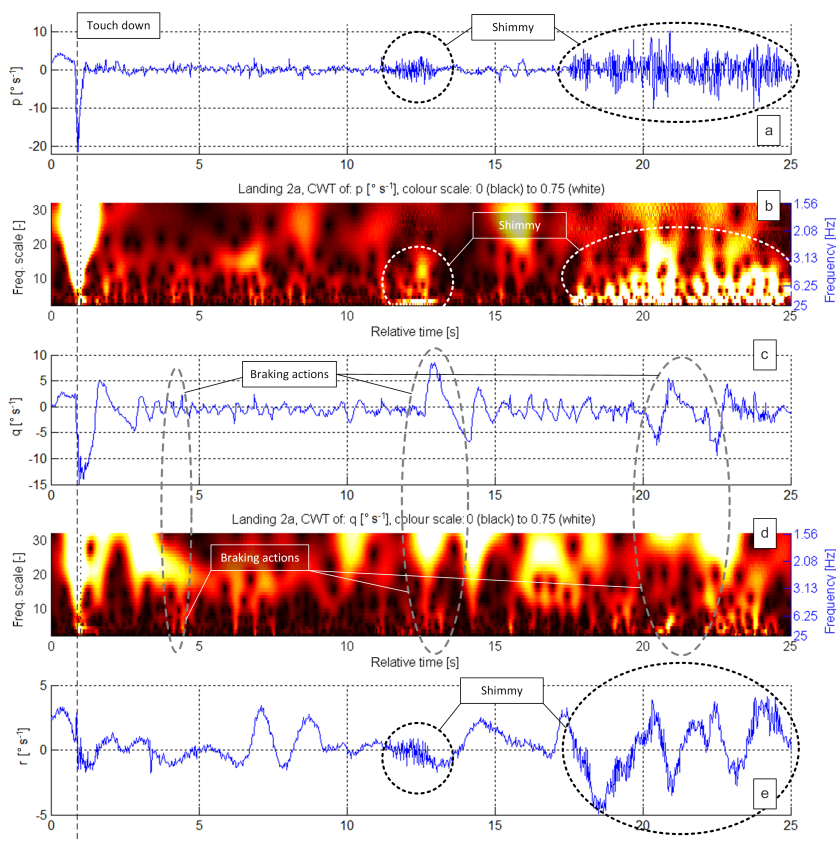

Landing 2a. CWT of $r^{\circ} \mathrm{s}^{-1]}$, colour scale: 0 (black) to 0.75 (White)

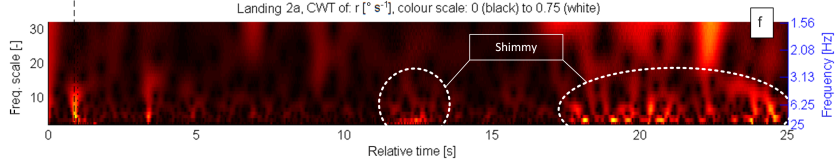

Figure 7. Angular velocities analysis recorded during the roll-off with shimmy vibrations of the front gear (CWT analysis); landing no. 2 a.

between the engine itself and rolling. After lift-off this band ceased, and frequencies of $5 \mathrm{~Hz}$ and higher are still visible (especially $p$, Fig. 10c). We presume that the main sources of the vibrations mentioned in flight are the engine and variation in N1 revolutions. Unfortunately, at this level, further analysis seems to be rather complicated, due to the fact that sampling frequency of the FDR is only $50 \mathrm{~Hz}$, which means the highest vibration frequency possible to detect is $25 \mathrm{~Hz}$. Concerning CWT analyses presented in Fig. 10, the complex Gauss wavelet was applied, due to the fact it enables the detection of oscillatory phenomena. The Morlet wavelet, applied for shimmy analysis, is more suitable for precise impact detection.

The frequencies below $1.5 \mathrm{~Hz}$ contain a wide set of natural frequencies of weathercocking and longitudinal motions (Goraj and Cichocka, 2016). In Fig. 10g, one may notice oscillations in pitch with mean frequency of $1.25 \mathrm{~Hz}$ (velocity $q$ ). Their amplitude is increasing in moments of levellingoff or when descent starts, but also during the approach to land. They may be explained as short-term pitch oscillations. Similarly, a Dutch roll motion may be identified. In Fig. 10j, there is a constant directional motion with mean frequency of $0.7 \mathrm{~Hz}$ motion (velocity $r$ ), which is correlated with $p$ oscillations of the same frequency (Fig. 10d). 

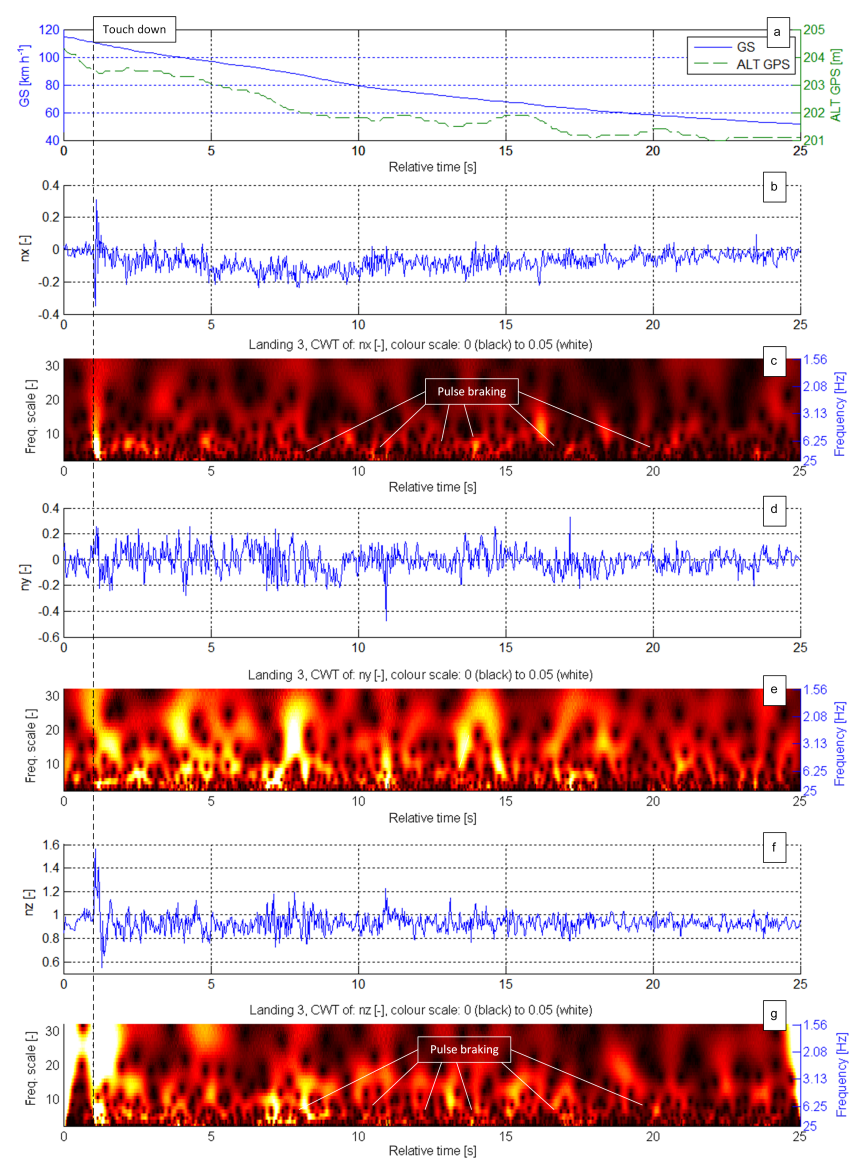

Figure 8. Load-factor analysis, recorded during the roll-off without shimmy vibrations of the front gear (CWT analysis); landing no. 3.

In Fig. 10j note also the weak oscillations of $r$ with mean frequency of $1.25 \mathrm{~Hz}$. We presume that the source would lie in gyroscopic moments caused by longitudinal oscillations with similar frequency.

The aeroplane control may also have forms of oscillations, especially when man-machine feedback loop is cauterised by short time constants (Rzucidło and Chudy, 2012). Such behaviour may occur when the pilot is focussed on precise flight parameters, e.g. during precision approach and landing or following a certain trajectory defined by dedicated flight instruments in both examples. While the aeroplane approaches the runway, the time constant is shorter as the threshold gets closer, and therefore the control frequencies are higher. Although all landings during the flight test campaign were performed with reference to the external objects (not instrumental), the analysis revealed similar behaviour. In Fig. 10d the roll frequency during take-off and final approach is close to $0.4 \mathrm{~Hz}$, but in the entire flight it is much lower, about $0.2 \mathrm{~Hz}$.
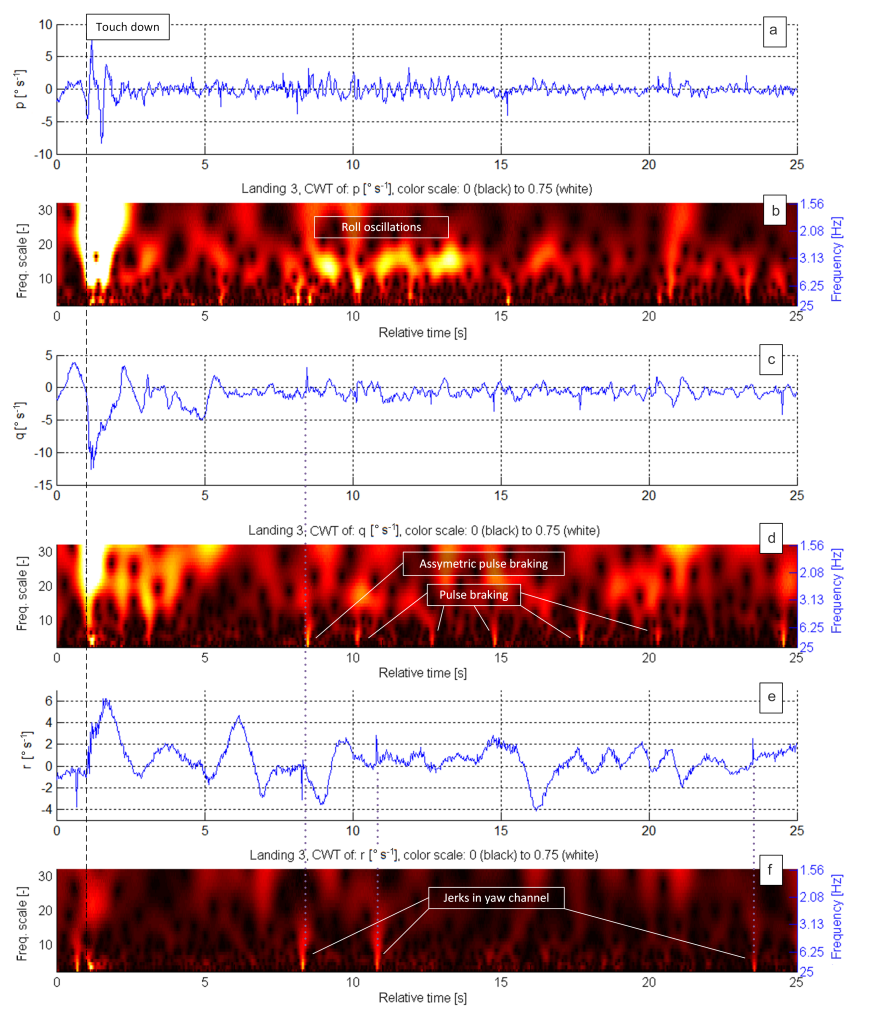

Figure 9. Angular velocities analysis recorded during the roll-off without shimmy vibrations of the front gear (CWT analysis); landing no. 3 .

\section{Summary}

In the presented paper, authors introduced examples of continuous wavelet analysis of load spectra recorded with MEMS gyroscopes during the flight testing.

The continuous wavelet analysis of accelerations and angular velocities, supplemented with time plots of several other parameters, when appropriate, and having a description of the flight provided by the pilot, could be applied for aeroplane load analysis during the flight based on data from a simple recorder unit.

The wavelet analysis techniques make easier the interpretation of high-frequency vibrations of airframe induced by propulsion, undercarriage and the airframe itself (Smith et al. 2007; Bakunowicz and Rzucidło, 2016), as well as the phenomena which take place in flight, such as Dutch rolls, short period oscillations (Naruoka et al., 2010; Feroz and Kandagal, 2016; Lichota et al., 2016), gyroscopic torques and ice accretion (Chang et al., 2016), but also man-machine interactions (Rzucidło and Chudy, 2012). There is also possibility to identify several long-term phenomena, such as phugoids or gusts. 

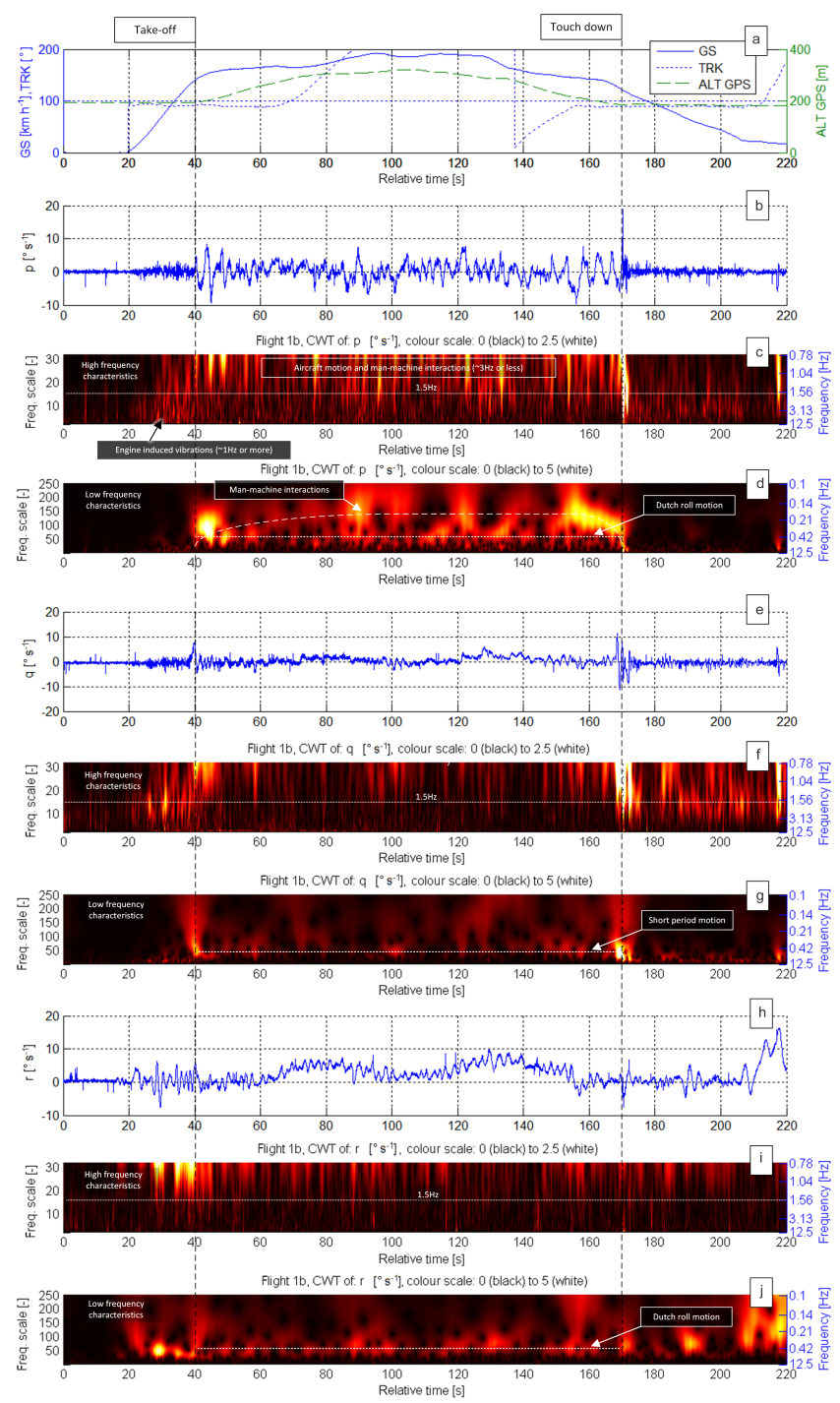

Figure 10. Angular velocities analysis recorded during a short "hoop" between two parallel runways (CWT analysis); flight no. $1 \mathrm{~b}$.

This paper introduces the method, which seems to be worthwhile for further development, especially towards higher frequencies. Regarding such phenomena as flutter or comparison with ground vibration tests (GVTs), a recording device with a sampling frequency of at least $200 \mathrm{~Hz}$ should be applied. The lowest eigenvalues for the I-31T aeroplane start at $8-9 \mathrm{~Hz}$ and concern less probable modes. The eigenvalues connected with airframe deformation, which may result in a flutter, start at $25 \mathrm{~Hz}$ (Cieślak et al., 2015).
The results of the analysis also allow the identification of flight characteristics of the aeroplane. At this level we may not consider them as full handling-quality analyses due to the fact that several other parameters are still missing.

The other potential application of this method would be academic education. The courses of data analysis, handling qualities or flight testing seem to be still uncommon in aerospace engineering studies (Padfield, 2005). Rzeszów University of Technology has a flying laboratory based on a Piper Seneca V aeroplane, equipped with additional devices on-board, including FDR, similar to the one described (Tomczyk et al., 2016), giving the opportunity to incorporate such analyses into study courses.

Data availability. The raw data from measurements are in the archives of the ESPOSA project. Inquiries and requests for details are welcomed and should be directed to the corresponding author. 


\section{Appendix A}

List of abbreviations and symbols ADC

AHRS

ALT GPS

AR1

CAN

CI

CWT

ESPOSA

FDR

FTE

GMWM

GNSS

GPS

GS

GVT

I-31T

MEMS

RMS

RPAS

RW

SD

SD card

WN

WV

$a_{x}, a_{y}, a_{z}$

$n_{x}, n_{y}, n_{z}$

$p, q, r$

$\Phi, \Theta, \Psi$

$f$

$g$
Air data computer

Attitude heading reference system

GPS altitude

First-order auto-regressive process

Controller area network

Confidence intervals

Continuous wavelet transform

Efficient Systems and Propulsion for Small Aircraft (7th Framework Program)

Flight data recorder

Flight test engineer

Generalized method of wavelet moments

Global navigation satellite system

Global positioning system

Ground speed

Ground vibration test

Experimental low-power single-engine turbo-propeller aeroplane

Micro-electro-mechanical systems

Root mean square

Remotely piloted aircraft system

Random walk

Spectral density

Secure digital card

White noise

Wavelet variance

Linear accelerations in body frame $\left(\mathrm{m} \mathrm{s}^{-1}\right)$

Linear accelerations in body frame relative to $g(-)$

Angular velocities (degree $\mathrm{s}^{-1}$ )

Roll, pitch and yaw angle $\left(^{\circ}\right)$

Frequency $(\mathrm{Hz})$

Standard gravity constant: $9.80665 \mathrm{~m} \mathrm{~s}^{-2}$ 
Competing interests. The authors declare that they have no conflict of interest.

Acknowledgements. The paper presents results of research done within the project ESPOSA (Efficient Systems and Propulsion for Small Aircraft), co-funded by the European Commission in 7th Framework Program (grant agreement 284859) and financial sources for science in the period of 2011-2015 granted for the international co-funded project.

Edited by: M. Kraft

Reviewed by: three anonymous referees

\section{References}

Abbate, A., DeCusatis, C., and Das, P.: Wavelets and subbands: fundamentals and applications, Springer Science + Business Media, LLC, New York, doi:10.1007/978-1-4612-0113-7, 2002.

Augustine, N. R.: Augustine's Laws, Penguin Books, New York, 1987.

Bakunowicz, J.: Single engine turboprop aeroplane class in small air transport, Aircr. Eng. Aerosp. Tec., doi:10.1108/AEAT-01-20170009.R1, in press, 2017.

Bakunowicz, J. and Rzucidło, P.: Coupling of MEMS gyroscope application with wavelet analysis for detection of airframe oscillations in flight conditions, Proceeding 36th European Telemetry and Test Conference - 2016, Nuremberg, Germany, 59-68, doi:10.5162/etc2016/2.2, 2016.

Bakunowicz, J., Meyer, R., and Swiech, L.: Measuring structure deformations of a composite glider by optical means with onground and in-flight testing, Measurement Science and Technology, 27, 124013, doi:10.1088/0957-0233/27/12/124013, 2016.

Balamuta J., Guerrier S., Molinari R., and Yang W., A Computationally Efficient Framework for Automatic Inertial Sensor Calibration, ArXiv e-prints, https://arxiv.org/abs/1603.05297 (last access: 5 May 2017), 2016.

Baron, A.: Samolot Osobowy I-23 "Manager", Wybrane problemy badawcze, Instytut Lotnictwa, Warszawa, ISBN 978-83-6353901-6, 2012 (in Polish).

Chang, S., Leng, M., Wu, H., and Thompson, J.: Aircraft ice accretion prediction using neural network and wavelet packet transform, Airc. Eng. Aerosp. Tec. 88, 128-136, doi:10.1108/aeat-052014-0057, 2016.

Cieślak, S., Krzymień, W., and Lorenz Z.: Próby rezonansowe samolotu I-31T. Raport z badań, Instytut Lotnictwa w Warszawie, 2015 (in Polish) (unpublished).

Doolitle, J. H.: Accelerations in flight, NACA TR-203, Washington, 1923.

EASA: Certification Specifications for Normal, Utility, Aerobatic and Commuter Category Aeroplanes CS-23, Amendment 1, 2009.

Efficient Systems and Propulsion for Small Aircraft (ESPOSA): Description of Work, Grant agreement no: 284859, 2016.

Feroz, A. and Kandagal, S. B.: Modal Identification of Aircraft Wing Coupled Heave-Pitch Modes Using Wavelet Packet Decomposition and Logarithmic Decrement, Procedia Engineering 144, 435-443, doi:10.1016/j.proeng.2016.05.153, 2016.
Goraj, Z. J. and Cichocka, E.: Influence of weak and strong gyroscopic effects, Aircr. Eng. Aerosp. Tec., 88, 613-622, doi:10.1108/AEAT-03-2015-0076, 2016.

Guerrier, S., Skaloud, J., Stebler, Y., and Victoria-Feser, M. P.: Wavelet-Variance-Based Estimation for Composite Stochastic Processes, J. Am. Stat. Assoc., 108, 1021-1030, doi:10.1080/01621459.2013.799920, 2013.

Guillaume, M., Uebersax, A., Mandanis, G., and Huber, C.: Structural Integrity - Yesterday - Today - Tomorrow, 11th International Fatigue Congress, Melbourne, 2014 Book Series: Advanced Materials Research Vol. 891-892, 1053-1058, doi:10.4028/www.scientific.net/amr.891-892.1053, 2014.

Harper, R. P. and Cooper, G. E.: Handling Qualities and Pilot Evaluation, J. Guid. Control Dynam., 9, 515-529, 1986.

Kopecki, G. and Rogalski, T.: Aircraft attitude calculation with the use of aerodynamic flight data as correction signals, Aerospace Sci. Tech., 32, 267-273, doi:10.1016/j.ast.2013.10.009, 2013.

Kopecki, G. and Rzucidło, P.: Integrated modular measurement system for in-flight tests. Polskie Towarzystwo Diagnostyki Technicznej, Diagnostyka, 15, 53-60, doi:10.1088/09570233/27/5/054003, 2014.

Kopecki, G., Tomczyk, A., and Rzucidło, P.: Algorithms of Measurement System for a Micro UAV, Mechatronic Systems and Materials IV, Solid State Phenomena, Vol. 198, Trans Tech Publications Inc., Zurich, 165-170, doi:10.4028/www.scientific.net/ssp.198.165, 2013.

Lichota, P., Ohme, P., and Sibilski, K.: Simultaneous Multistep Excitations for Aircraft System Identification, AIAA Atmospheric Flight Mechanics Conference, Washington D.C, doi:10.2514/6.2016-3704, 2016.

Liu, J., Hang, Y., Li, R., and Sun, Y.: Optimization design technology of environmental worthiness for MEMS inertial attitude reference system, Nanjing Hangkong Hangtian Daxue Xuebao/Journal of Nanjing University of Aeronautics and Astronautics 44, 669-676, doi:10.1108/aeat-05-2014-0057, 2012.

Lowry, J. T.: Performance of Light Aircraft, AIAA, Reston, 1999.

Majka, A.: Multiple objective optimisation of the power unit for a very light jet, Aircr. Eng. Aerosp. Tec., 86, 234-241, doi:10.1108/aeat-01-2013-0010, 2014.

McFarland, M. W.: The Papers of Wilbur and Orville Wright, McGraw-Hill, New York, 1953.

Naruoka, M., Hino, T., Nakagawa, R., Tsuchiya, T., and Suzuki S.: System Identification of Small UAVs with MEMS-Based Avionics, AIAA Infotech@Aerospace Conference, Seattle, Washington, doi:10.2514/6.2009-1907, 2009.

Naruoka, M., Hino, T., and Tsuchiya, T.: Application of Wavelet Transform to System Identification of Small UAVs Flight Characteristic, AIAA 2010-3536 paper, AIAA Infotech@ Aerospace 2010, Atlanta, Georgia, doi:10.2514/6.2010-3536, 2010.

Norton, W. J.: Structures Flight Test Handbook, AFFTC-TIH-90001, Edwards Air Force Base, Lancaster, 1990.

Padfield, G. D.: Flight Handling Qualities, A Problem-BasedLearning Module for Final Year Aerospace Engineering Students, 1st Annual CDIO Conference, Queen's University, Ontario, 2005.

Piwek, K. and Wiśniowski, W.: Small air transport aircraft entry requirements evoked by FlightPath 2050, Aircr. Eng. Aerosp. Tec., 88, 341-347, doi:10.1108/AEAT-02-2015-0065, 2016. 
Rydlo, K., Rzucidlo, P., and Chudy, P.: Simulation and prototyping of FCS for sport aircraft, Aircr. Eng. Aerosp. Tec., 85, 475-486, doi:10.1108/aeat-10-2012-0186, 2013.

Rzucidło, P. and Chudy, P.: Analysis of Interactions between Pilot-Operator and Advanced Flight Control System, Mechatronic Systems, Mechanics and Materials, Solid State Phenomena, Vol. 180, Trans Tech Publications Ltd, 101-108, doi:10.4028/www.scientific.net/ssp.180.101, 2012.

Rzucidło, P., Kopecki, G. H., deGroot, K., Kucaba-Pietal, A., Smusz, R., Szewczyk, M., and Szumski, M.: Data acquisition system for PW-6U in flight boundary layer mapping, Aircr. Eng. Aerosp. Tec., 88, 572-579, doi:10.1108/AEAT-12-2014-0215, 2016.

Sipos, M., Paces, P., Rohac, J., and Novacek, P.: 2012, Analyses of Triaxial Accelerometer Calibration Algorithms, IEEE Sens. J., 12, 1157-1165, 2012.
Smith, C., Akujuobi, C. M., Hamory, P., and Kloesel K.: An approach to vibration analysis using wavelets in an application of aircraft health monitoring, Mech. Syst. Signal Pr., 21, 12551272, doi:10.1016/j.ymssp.2006.06.008, 2007.

Tomczyk, A., Bakunowicz, J., and Wałek, Ł.: Simplified Total in Flight Simulator as a Tool in the Aeronautics Students' Education, 8th World Conference on Educational Sciences, University of Alcala, Spain, 2016.

Wright, J. R. and Cooper, J. E.: Introduction to Aircraft Aeroelasticity and Loads, Second Edn., John Wiley \& Sons, Ltd, Chichester, West Sussex, 2015. 